Humboldt (Stoney) Lake in 1960. F illustrates an example of a colony of Gloeotrichia which consists of filaments extending radially from a mutual centre. To take the photograph the colony was crushed. Oscillatoria, photo $\mathrm{G}$, is a common filamentous form occurring in lakes in the fall. It was abundant under the ice in Wakaw Lake in February, 1961. This genus is also interesting from the sitandpoint of being able to move freely. The movements are of two kinds. One is a horizontal, backand-forth movement while the other involves a terminal waving of the filament.

Blue-green algae have presented several problems. They have a detrimental effect on resiort areas when blooms form and collect in bathing areas. Besides affecting swimming, water skiing and fishing adversely, the decomposition of a bloom may result in obnoxious ador and appearance. Aphanizomenon, Anabaena and Microcystis seem to be the main offenders in this province. Algal toxicity may be associated with blooms. Five different species have been found to be responsible for animal deaths in different parts of the world. Although the five species occur in Saskatchewan only Aphanizomenon, Anabaena flos-aquae and Microcystis occur in sufficient quantities to warrant suspicion here. Cattle, horses, swine, dogs and fowl are all reported to have died after drinking water containing blue-green algae. However, even when these species are present, algal blooms are only infrequently toxic. To test for toxicity, white mice are injected with up to $1 \mathrm{cc}$. of the algal bloom into the abdominal cavity. If toxic it will produce death within a few minutes. In Microcystis the toxin is known to be a polypeptide. No cases of algal poisoning by blue-greens has ever been proved in humans although cases of enteritis (intestinal disorders) sieemis to incriminci.e them.

Water blooms lead iso problems in human water supply as well. They may clog filters and produce tastes that must be removed in water purification plants. Where dense blooms occur the algae may use up the oxygen supply in the water for their own respiration during the night. This oxygen depletion may result in fish kills.

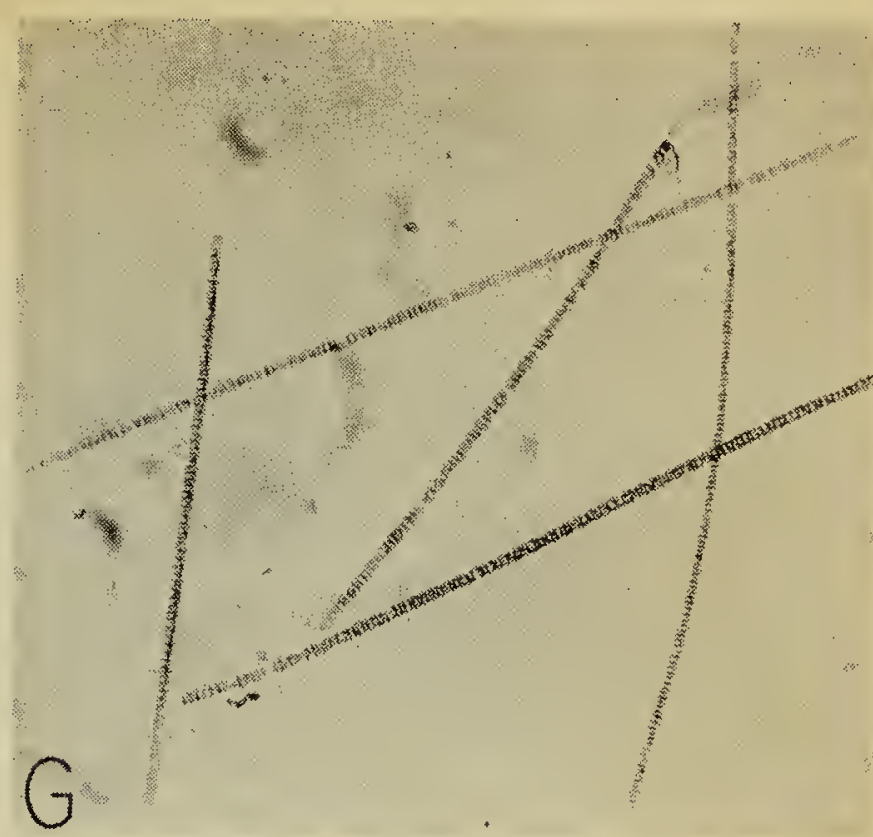

Copper sulphate (and cither chemicals) can be applied to a lake to kill these algae. Although effective, its use is restricted by the high cost of purchase and application of the chemical.

Blue-green algae may be of some practical use. It is well known that some of them, such as some species of Anabaena, fix nitrogen in the form of nitrates. These are then available to other plants which may be important initially in the cycle of life in lakes and ultimately in fish production. This is made use of directly in the growing of rice in Asia. The blue-greens fix nitrogen which is then used by the rice. The algae are then eaten by carp which are utilized as food. Although they are ingested by rough fish in our lakes, it is not known whether they are actually digested by these fish and thus play a part in the food chain.

A knowledge of the Myxophycaea opens up one more segment of the living world, a segment which is filled with a varieity of life forms of interest to the curious.

\section{WEEPING POPLAR}

Mr. B. Weloer of Sedgewick, Alberta, sent in two pictures of trees growing in his pasture. These trees seem similar to typical poplars but they have weeping branches. Since it would be difficult to identify the poplars from the pictures Mr. Weber should send a pressed sample (flowers and fruits as well as leaves) to the Botany Department, University of Alberta, at Edmonton, or to Dr. E. H. Moss, 1110187 Ave., Edmonton. 